\title{
OPEN The epidemiology of fracture-related infections in Germany
}

\author{
Nike Walter ${ }^{1,2,3}$, Markus Rupp ${ }^{1,3 凶}$, Siegmund Lang ${ }^{1} \&$ Volker Alt ${ }^{1}$
}

The epidemiology of fracture-related infection (FRI) is unknown, which makes it difficult to estimate future demands and evaluate progress in infection prevention. Therefore, we aimed to determine the nationwide burden's development over the last decade as a function of age group and gender. FRI prevalence as a function of age group and gender was quantified based on annual ICD-10 diagnosis codes from German medical institutions between 2008 through 2018, provided by the Federal Statistical Office of Germany (Destatis). The prevalence of FRI increased by 0.28 from 8.4 cases per 100,000 inhabitants to 10.7 cases per 100,000 inhabitants between 2008 and 2018. The proportion of fractures resulting in FRI increased from 1.05 to $1.23 \%$. Gender distribution was equal. Patients aged 60-69 years and 70-79 years comprised the largest internal proportion with $20.2 \%$ and $20.7 \%$, respectively, whereby prevalence increased with age group. A trend towards more diagnoses in older patients was observed with a growth rate of 0.63 for patients older than 90 years. Increasing rates of fracture-related infection especially in older patients indicate an upcoming challenge for stakeholders in health care systems. Newly emerging treatment strategies, prevention methods and interdisciplinary approaches are strongly required.

In trauma surgery, reduction and internal fixation is applied to restore skeletal integrity. One of the major complications after fracture fixation utilizing metallic fracture fixation devices, is implant related infection, which in general requires surgical treatment Depending on several factors, at least one, but often two or even multiple staged surgeries are needed for eradication of infection and finally bony consolidation ${ }^{1}$. In the literature, rates of developing a posttraumatic infection are reported to be around 1-2\% for closed fractures ranging up to exceeding $30 \%$ for Gustilo-Anderson type III open tibia fractures ${ }^{2-4}$. Considering studies showing that incidences of long bone fractures increase ${ }^{5}$, numbers of infection complications can be expected to rise as well.

Depending on injury severity, success rates only vary between $70-90 \%$ with a recurrence of the infection in $6-9 \%$ of the patients ${ }^{1,6,7}$. Among others, consequences are significantly reduced patient-reported quality of life and multiplied healthcare costs up to 6.5 times $^{8,9}$. Hence, much effort has been made in prevention approaches $^{2,10-12}$.

However, current socioeconomic calculations are based on small patient numbers and the exact prevalence of fracture-related infection is unknown. Therefore, it remains difficult to estimate future demands foresee developments and evaluate the progress in infection prevention methods. To this end, we aimed at determining the nationwide burden and analysing recent trends in fracture-related infections.

\section{Material and methods}

Data consisting of annual ICD-10 diagnosis codes from German medical institutions between 2008 through 2018 was provided by the Federal Statistical Office of Germany (Destatis). The ICD-10 code "T84.6, infection and inflammatory reaction due to internal fixation device" was used to identify patients aged 20 years or older diagnosed with FRI. A detailed breakdown of these data by age group and gender was performed. Prevalence rates were calculated based on Germany's historical population aged 20 years or older provided by Destatis ${ }^{13}$. Here, the number of inhabitants in each of the 16 German federal states was considered by year of birth for each year of the period 2008 through 2018. The deadline of each year was December 31 . The proportion of FRI was calculated based on total numbers of fracture diagnoses. Here, the ICD-10 codes shown in Table 1 were used (Table 1). Data were analyzed using the statistical software SPSS Version 26.0 (IBM, SPSS Inc. Armonk, NY, USA).

${ }^{1}$ Department for Trauma Surgery, University Medical Center Regensburg, Franz-Josef-Strauß-Allee 11, 93053 Regensburg, Germany. ${ }^{2}$ Department for Psychosomatic Medicine, University Medical Center Regensburg, Regensburg, Germany. ${ }^{3}$ These authors contributed equally: Nike Walter and Markus Rupp. ${ }^{\square}$ email: markus.rupp@ ukr.de 


\begin{tabular}{|l|l|l|l|}
\hline ICD-10 code & Description & ICD-10 code & Description \\
\hline S32.1 & Sacrum fracture & S72.0 & Femur neck fracture \\
\hline S32.2 & Coccyx fracture & S72.1 & Pertrochanteric femur fracture \\
\hline S32.3 & Ilium fracture & S72.2 & Subtrochanteric femur fracture \\
\hline S32.4 & Acetabulum fracture & S72.3 & Femur shaft fracture \\
\hline S32.5 & Pubis fracture & S72.4 & Distal femur fracture \\
\hline S32.6 & Ischium fracture & S82.0 & Patella fracture \\
\hline S32.8 & Fracture of other parts of pelvis & S82.1 & Proximal tibia fracture \\
\hline S42.0 & Clavicle fracture & S82.2 & Tibia shaft fracture \\
\hline S42.1 & Scapula fracture & S82.3 & Distal tibia fracture \\
\hline S42.2 & Proximal humerus fracture & S82.4 & Fibula shaft fracture \\
\hline S42.3 & Humerus shaft fracture & S82.5 & Medial malleolus fracture \\
\hline S42.4 & Distal humerus fracture & S82.6 & Lateral malleolus fracture \\
\hline S52.0 & Proximal ulna fracture & S92.0 & Calcaneus fracture \\
\hline S52.1 & Proximal radius fracture & S92.1 & Talus fracture \\
\hline S52.2 & Ulna shaft fracture & S92.2 & Other tarsal bone(s) fracture \\
\hline S52.3 & Radius shaft fracture & S92.3 & Metatarsal bone(s) fracture \\
\hline S52.5 & Distal radius fracture & & \\
\hline S62.0 & Scaphoid fracture & & \\
\hline S62.1 & Carpal bone fracture & & \\
\hline S62.2 & First metacarpal bone fracture & & \\
\hline S62.3 & Other metacarpal bones fracture & & \\
\hline
\end{tabular}

Table 1. Used ICD-10 code to calculate total numbers of fractures with descriptions.

\begin{tabular}{|c|c|c|c|c|c|c|}
\hline Year & Total numbers & $\begin{array}{l}\text { German population } 20 \text { years } \\
\text { or older }\end{array}$ & $\begin{array}{l}\text { Prevalence per 100,000 } \\
\text { inhabitants }\end{array}$ & Growth rate (relative to 2008) & Fractures total numbers & Proportion of FRI \\
\hline 2008 & 5556 & $66,346,045$ & 8.4 & - & 534,131 & 1.04 \\
\hline 2009 & 6091 & $66,400,066$ & 9.2 & 0.10 & 578,897 & 1.05 \\
\hline 2010 & 6503 & $66,549,975$ & 9.8 & 0.17 & 553,012 & 1.18 \\
\hline 2011 & 6800 & $65,398,514$ & 10.4 & 0.24 & 547,319 & 1.24 \\
\hline 2012 & 6735 & $65,665,069$ & 10.3 & 0.22 & 556,766 & 1.21 \\
\hline 2013 & 6985 & $65,943,867$ & 10.6 & 0.26 & 547,683 & 1.28 \\
\hline 2014 & 6882 & $66,677,665$ & 10.3 & 0.23 & 562,294 & 1.22 \\
\hline 2015 & 7206 & $67,097,676$ & 10.7 & 0.28 & 568,598 & 1.27 \\
\hline 2016 & 7024 & $67,440,230$ & 10.4 & 0.24 & 580,975 & 1.21 \\
\hline 2017 & 7228 & $67,540,025$ & 10.7 & 0.28 & 585,891 & 1.23 \\
\hline 2018 & 7253 & $67,724,921$ & 10.7 & 0.28 & 587,612 & 1.23 \\
\hline
\end{tabular}

Table 2. Historic development of population and fracture-related infection prevalence from 2008 through 2018.

\section{Results}

In 2018, a total number of 7253 FRI cases were listed in Germany. In comparison to 5556 cases in 2008, the overall prevalence substantially increased with a growth rate of 0.28 from 8.4 cases per 100,000 inhabitants to 10.7 cases per 100,000 inhabitants. Accordingly, the proportion of fractures resulting in FRI increased from 1.04 to $1.23 \%$ (Table 2 ).

The internal gender distribution was equal with $50.8 \%$ male cases and $49.2 \%$ cases in 2018 , whereby the prevalence of FRI was slightly higher in the male population (11.1 cases per 100,000 inhabitants) than for the female population (10.3 cases per 100,000 inhabitants) (Fig. 1, Table 3 ).

Regarding the prevalence for distinct age groups, cases per 100,000 inhabitants steadily increased with age. For 2018, 35 cases were calculated per 100,000 per inhabitants aged 90 years or older, 24.9 cases per 100,000 per inhabitants aged $80-89$ years and 19.5 cases per 100,000 per inhabitants aged 70-79 years, whereas only 3.4 cases were estimated per 100,000 per inhabitants aged 20-29 years and 4.1 cases per 100,000 per inhabitants aged 30-39 years. Relative to the year 2008, a trend towards more FRI diagnoses in older patients can be observed. Highest growth rates were found for patients aged 90 years or older $(0.63)$ and patients aged $70-79$ years $(0.28)$ (Table 4, Fig. 2). 


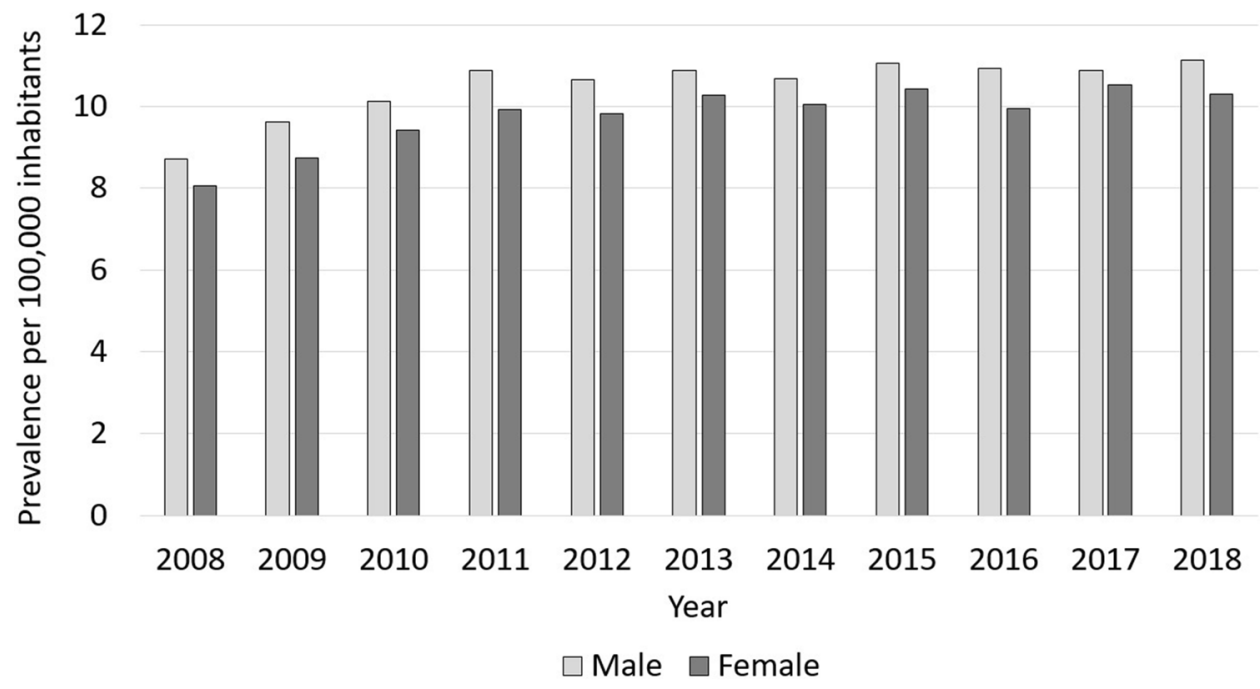

Figure 1. Development of FRI prevalence from 2008 to 2018. The prevalence of men diagnosed with FRI is shown in light grey, the prevalence of female cases is illustrated in dark grey.

\begin{tabular}{|c|c|c|c|c|c|c|}
\hline \multirow[b]{2}{*}{ Year } & \multicolumn{3}{|l|}{ Male cases } & \multirow{2}{*}{\begin{tabular}{|l|} 
Female cases \\
$\begin{array}{l}\text { Total number } \\
\text { (percentage) }\end{array}$ \\
\end{tabular}} & \multirow[b]{2}{*}{$\begin{array}{l}\text { Prevalence per 100,000 } \\
\text { female inhabitants }\end{array}$} & \multirow[b]{2}{*}{$\begin{array}{l}\text { Growth rate (relative to } \\
\text { 2008) }\end{array}$} \\
\hline & $\begin{array}{l}\text { Total numbers } \\
\text { (percentage) }\end{array}$ & $\begin{array}{l}\text { Prevalence per 100,000 } \\
\text { male inhabitants }\end{array}$ & $\begin{array}{l}\text { Growth rate (relative to } \\
\text { 2008) }\end{array}$ & & & \\
\hline 2008 & $2802(50.4)$ & 8.7 & - & 2754 (49.6) & 8.0 & - \\
\hline 2009 & $3104(51.0)$ & 9.6 & 0.11 & $2987(49.0)$ & 8.7 & 0.08 \\
\hline 2010 & $3275(50.4)$ & 10.1 & 0.16 & $3228(49.6)$ & 9.4 & 0.17 \\
\hline 2011 & $3440(50.6)$ & 10.9 & 0.25 & $3360(49.4)$ & 9.9 & 0.23 \\
\hline 2012 & $3394(50.4)$ & 10.7 & 0.22 & $3341(49.6)$ & 9.8 & 0.22 \\
\hline 2013 & $3482(49.8)$ & 10.9 & 0.25 & $3503(50.2)$ & 10.3 & 0.28 \\
\hline 2014 & $3447(50.1)$ & 10.7 & 0.23 & 3435 (49.9) & 10.0 & 0.25 \\
\hline 2015 & $3619(50.2)$ & 11.1 & 0.27 & 3587 (49.8) & 10.4 & 0.30 \\
\hline 2016 & $3591(51.1)$ & 10.9 & 0.26 & $3433(48.9)$ & 10.0 & 0.24 \\
\hline 2017 & 3586 (49.6), & 10.9 & 0.25 & $3642(50.4)$ & 10.5 & 0.31 \\
\hline 2018 & $3682(50.8)$ & 11.1 & 0.28 & $3571(49.2)$ & 10.3 & 0.28 \\
\hline
\end{tabular}

Table 3. Historic development from 2008 through 2018 of all fracture-related infection cases as a function of gender.

Regarding the constituent ratio, explaining the internal proportion of infection, in 2018 patients aged $70-79$ years comprised the largest cohort with $20.7 \%$, followed by patients aged $60-69$ years $(20.2 \%)$ and patients aged 50-59 years (19.3\%). Comparing the age distribution as a function of gender, it becomes apparent that older patients were predominantly female. For instance, $6.30 \%$ of female cases were aged 90 years or older compared to $1.11 \%$ male cases, $23.47 \%$ female patients aged $80-89$ years versus $8.58 \%$ male cases in this increment and $24.64 \%$ women aged $70-79$ years in relation to $16.89 \%$ men of this age. In the age increments $50-59$ years, more male cases were registered than female cases (23.60\% versus $14.84 \%)$. The same applied for patients aged $40-49$ years with $13.17 \%$ male cases compared to $6.05 \%$ affected women (Fig. 3 ).

\section{Discussion}

In this population-based study, trends in the epidemiology of fracture-related infections were described and prevalence was analyzed as a function of gender and age group. To the best of our knowledge, this study is the first one describing the nationwide burden of FRI.

A literature review estimated that fracture-fixation device infections comprise $<5 \%$ of all implant associated infections ${ }^{14}$, whereas a single center cohort study at Geneva University Hospital pooling clinical data on orthopaedic infections reported that $24 \%$ of all cases involved osteosynthetic material ${ }^{15}$. In general, prevalence data on FRI vary in the literature. For instance, a multi-center study carried out in India included 787 participants with tibia fractures, estimating the incidence of infection as $1.6 \%$ for closed fractures and $8.0 \%$ for open fractures ${ }^{16}$, whereas Metsemakers and colleagues found an infection rate of $3.4 \%$ in a cohort of 358 patients with tibia fractures ${ }^{9}$. Blonna et al. reported an infection rate of $4 \%$ out of 452 proximal humeral fractures and Ovaska et al. identified $5 \%$ of 1923 consecutive ankle fractures to be infected ${ }^{17,18}$. One study carried out in Brazil found 


\begin{tabular}{|c|c|c|c|c|c|c|c|c|}
\hline Year & \begin{tabular}{|l|}
$20-29$ years \\
Total (percen- \\
tage), preva-lence
\end{tabular} & \begin{tabular}{|l|}
$30-39$ years \\
Total (percen- \\
tage), preva-lence
\end{tabular} & $\begin{array}{l}40-49 \text { years } \\
\text { Total (percen- } \\
\text { tage), preva-lence }\end{array}$ & $\begin{array}{l}\text { 50-59 years } \\
\text { Total (percen- } \\
\text { tage), preva-lence }\end{array}$ & $\begin{array}{l}\text { 60-69 years } \\
\text { Total (percen- } \\
\text { tage), preva-lence }\end{array}$ & $\begin{array}{l}\text { 70-79 years } \\
\text { Total (percen- } \\
\text { tage), preva-lence }\end{array}$ & $\begin{array}{l}80-89 \text { years } \\
\text { Total (percen- } \\
\text { tage), preva-lence }\end{array}$ & $\begin{array}{l}90 \text { years or older } \\
\text { Total (percen- } \\
\text { tage), preva-lence }\end{array}$ \\
\hline 2008 & $274(4.9), 2.8$ & $393(7.1), 3.8$ & 753 (13.6), 5.4 & $969(17.4), 8.6$ & $1136(20.4), 12.1$ & $1146(20.6), 15.2$ & 756 (13.6), 21.8 & $129(2.3), 21.5$ \\
\hline 2009 & $319(5.2), 3.2$ & $363(6.0), 3.6$ & $821(13.5), 5.9$ & 1035 (17.0), 9.0 & $1208(19.8), 13.1$ & $1355(22.2), 17.3$ & 859 (14.1), 24.1 & $131(2.2), 21.0$ \\
\hline 2010 & $324(5.0), 3.3$ & $368(5.7), 3.8$ & 827 (12.7), 6.0 & 1137 (17.5), 9.7 & $1326(20.4), 14.7$ & $1491(22.9), 18.3$ & 888 (13.7), 24.3 & $142(2.2), 21.8$ \\
\hline 2011 & $321(4.7), 3.3$ & 385 (5.7), 4.1 & $836(12.3), 6.3$ & $1251(18.4), 10.6$ & $1291(19.0), 14.6$ & $1587(23.3), 19.0$ & 973 (14.3), 26.8 & $156(2.3), 24.2$ \\
\hline 2012 & $283(4.2), 2.9$ & $384(5.7), 4.0$ & 823 (12.2), ), 6.4 & $1244(18.5), 10.3$ & $1271(18.9), 14.2$ & $1593(23.7), 18.9$ & 926 (13.7), 25.3 & $211(3.1), 31.7$ \\
\hline 2013 & $378(5.4), 3.9$ & $373(5.3), 3.9$ & 804 (11.5), 6.5 & $1284(18.4), 10.4$ & $1259(18.0), 14.0$ & $1716(24.6), 20.0$ & 971 (13.9), 26.4 & $200(2.9), 29.0$ \\
\hline 2014 & $322(4.7), 3.3$ & $360(5.2), 3.7$ & $710(10.3), 6.0$ & $1285(18.7), 10.1$ & $1289(18.7), 14.1$ & 1715 (24.9), 20.1 & 975 (14.2), 25.5 & $226(3.3), 31.6$ \\
\hline 2015 & $292(4.1), 2.9$ & $422(5.9), 4.2$ & 735 (10.2), 6.4 & $1382(19.2), 10.6$ & $1370(19.0), 14.4$ & $1647(22.9), 20.0$ & $1110(15.4), 27.7$ & $248(3.4), 34.5$ \\
\hline 2016 & $371(5.3), 3.7$ & $474(6.7), 4.6$ & $686(9.8), 6.2$ & $1320(18.8), 10.0$ & $1361(19.4), 13.8$ & $1579(22.5), 19.7$ & $11,012(14.4), 24.1$ & $221(3.1), 29.5$ \\
\hline 2017 & $345(4.8), 3.5$ & $459(6.4), 4.4$ & $659(9.1,6.1$ & $1438(19.9), 10.8$ & $1370(19.0), 13.6$ & $1588(22.0), 20.2$ & 1114 (15.4), 25.3 & $255(3.5), 33.8$ \\
\hline 2018 & $333(4.6), 3.4$ & $435(6.0), 4.1$ & $701(9.7), 6.7$ & $1399(19.3), 10.4$ & $1463(20.2), 14.2$ & $1502(20.7), 19.5$ & $1154(15.9), 24.9$ & 266 (3.7), 35.0 \\
\hline $\begin{array}{l}\text { Growth rate (2018 } \\
\text { relative to } 2008)\end{array}$ & 0.23 & 0.07 & 0.25 & 0.21 & 0.17 & 0.28 & 0.14 & 0.63 \\
\hline
\end{tabular}

Table 4. Historic development from 2008 through 2018 of all fracture-related infection cases as a function of age group. Data is shown as total numbers, percentage and prevalence per 100,000 inhabitants of the considered age group.



Figure 2. Development of FRI prevalence from 2008 to 2018 as a function of age group in 10-year increments.

an infection rate of $13.24 \%$, examining 142 patients with open fractures at various anatomical locations, whereas another one reported $18.8 \%$ infections in 133 patients with open fractures ${ }^{19,20}$. Additionally, a review on open femoral shaft fractures treated with intramedullary nailing estimated an infection rate of $6 \%$, whereas another review reported infection rates in the range of $0.9-11.6 \%$ comparing outcomes of open tibial fractures ${ }^{21,22}$. In light of the diversity of findings, describing the nationwide burden of FRI seems useful. Here, an overall FRI rate of $1.23 \%$ was estimated for the year 2018 based on calculated total numbers of fracture cases, which is lower than previously reported. Differences might be explainable by the distinct considered fracture types and sites, heterogeneity in the study design as well as center-specific treatment procedures.

Further, our analysis revealed that the prevalence of FRI increased with a rate of 0.28 from 8.4 cases per 100,000 inhabitants to 10.7 cases per 100,000 inhabitants between 2008 and 2018. The distribution of male and female cases was equal in our analysis, whereas research increasingly addresses immune response gender differences ${ }^{23,24}$. The observed trend towards more FRI diagnosis in older patients possibly reflects demographic changes such as population decline and aging, which challenge the healthcare system not only in Germany. In consideration that prevention strategies and improved treatment algorithms for optimal patient care moved into focus of orthopedic research ${ }^{2,10,25}$, the increase of infection rates over the last decade seems surprisingly high. This might be attributable to heightened prevalence of obesity, which has risen substantially and the fact that Germany is rated among the countries with the highest prevalence of tobacco use in Europe ${ }^{26,27}$. Further, an extrapolation of hospital-based data to the German population revealed 16,742 severely injured persons per year and at least 5.8 million German inhabitants have received a medical diagnosis of type 2 diabetes, which may contribute to rising FRI numbers ${ }^{28-30}$. 

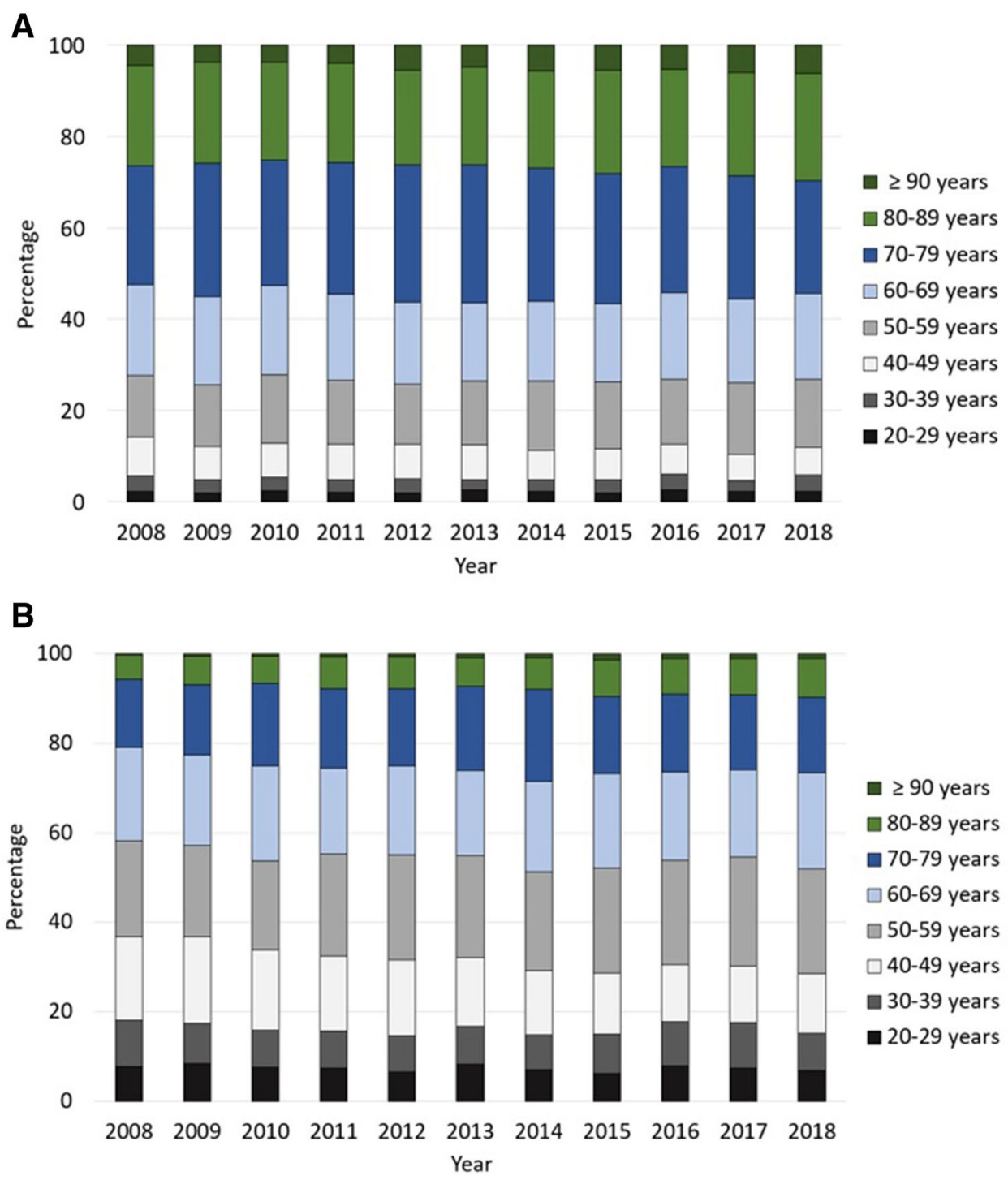

Figure 3. (A) Development of the internal proportion of male FRI cases divided by age group. (B) Development of the internal proportion of female FRI cases divided by age group.

Our study shows several limitations. First, the ICD-10 codes do not allow a differentiation regarding anatomical localization, classification of fractures as well as surgical treatment strategies. Further, it was not possible to derive individual features of the patients and risk factors such as obesity, smoking and comorbidities. Also, no statement about underlying pathogens causing the infection can be made. Finally, analyzing large registry data does not allow to apply in every treated case the FRI diagnosis criteria recently described by a consensus group ${ }^{31}$. This downside goes hand in hand with the upside of analyzing a complete data set, since all patients treated for FRI, which is in general an inpatient procedure have been coded by the OPS-code T84.6.

In conclusion, in light of a strong increase especially in elderly patients, prevention strategies, improved treatment strategies and an interdisciplinary treatment approaches are strongly required.

\section{Data availability}

The datasets analysed during the current study are available from the corresponding author on reasonable request.

Received: 18 December 2020; Accepted: 5 May 2021

Published online: 17 May 2021

\section{References}

1. Metsemakers, W. J. et al. Infection after fracture fixation: current surgical and microbiological concepts. Injury 49(3), 511-522 (2018).

2. Metsemakers, W. J. et al. Prevention of fracture-related infection: a multidisciplinary care package. Int. Orthop. 41(12), 2457-2469 (2017). 
3. Trampuz, A. \& Zimmerli, W. Diagnosis and treatment of infections associated with fracture fixation devices. Injury 37, 59-66 (2006).

4. Ktistakis, I., Giannoudi, M. \& Giannoudis, P. V. Infection rates after open tibial fractures: are they decreasing?. Injury 45, 1025 (2014).

5. Amin, S., Achenbach, S. J., Atkinson, E. J., Khosla, S. \& Melton, L. J. 3rd. Trends in fracture incidence: a population-based study over 20 years. J. Bone Miner. Res. 29(3), 581-589 (2014).

6. Bezstarosti, H. et al. Insights into treatment and outcome of fracture-related infection: a systematic literature review. Arch. Orthop. Trauma Surg. 139(1), 61-72 (2019).

7. Bose, D., Kugan, R., Stubbs, D. \& McNally, M. Management of infected nonunion of the long bones by a multidisciplinary team. Bone Joint J. 97-B(6), 814-817 (2015).

8. Bowen, C. V., Botsford, D. J., Hudak, P. L. \& Evans, P. J. Microsurgical treatment of septic nonunion of the tibia. Quality of life results. Clin. Orthop. Relat. Res. 332, 52-61 (1996).

9. Metsemakers, W. J., Smeets, B., Nijs, S. \& Hoekstra, H. Infection after fracture fixation of the tibia: analysis of healthcare utilization and related costs. Injury 48(6), 1204-2121 (2017).

10. Rupp, M., Popp, D. \& Alt, V. Prevention of infection in open fractures: where are the pendulums now?. Injury 51(Suppl 2), 57-63. https://doi.org/10.1016/j.injury.2019.10.074 (2020).

11. Foster, A. L. et al. Fracture-related infection: current methods for prevention and treatment. Expert Rev Anti Infect. Ther. 18(4), 307-321 (2020).

12. Alt, V. Antimicrobial coated implants in trauma and orthopaedics-A clinical review and risk-benefit analysis. Injury 48(3), 599-607 (2017).

13. Statistisches Bundesamt (Destatis), http://www-genesis.destatis.de/genesis/online. Accessed November 25, 2020.

14. Wekwejt, M., Dziabuszewska, M. \& Palubicka, A. The problem of infections associated with implants-an overview. Eur. J. Med. Technol. 4(21), 19-26 (2018).

15. Cuérel, C. et al. Clinical and epidemiological differences between implant-associated and implant-free orthopaedic infections. Eur. J. Orthop. Surg. Traumatol. 27(2), 229-231 (2017).

16. Doshi, P. et al. Incidence of infection following internal fixation of open and closed tibia fractures in India (INFINITI): a multicentre observational cohort study. BMC Musculoskelet. Disord. 18(1), 156 (2017).

17. Ovaska, M. T. et al. Predictors of poor outcomes following deep infection after internal fixation of ankle fractures. Injury 44(7), 1002-1006 (2013).

18. Blonna, D. et al. Incidence and risk factors for acute infection after proximal humeral fractures: a multicenter study. J. Shoulder Elbow Surg. 23(4), 528-535 (2014).

19. Guerra, M., Gregio, F. M., Bernardi, A. \& Castro, C. C. Infection rate in adult patients with open fractures treated at the emergency hospital and at the ULBRA university hospital in Canoas, Rio Grande do Sul, Brazil . Rev. Brasil. Ortopedia 52(5), 544-548 (2017).

20. Fernandes, M. et al. Open fractures and the incidence of infection in the surgical debridement 6 hours after trauma. Acta Ortop. Bras. 23(1), 38-42 (2015).

21. Saleeb, H., Tosounidis, T., Papakostidis, C. \& Giannoudis, P. V. Incidence of deep infection, union and malunion for open diaphyseal femoral shaft fractures treated with IM nailing: a systematic review. Surgeon 17(5), 257-269 (2019).

22. Papakostidis, C. et al. Prevalence of complications of open tibial shaft fractures stratified as per the Gustilo-Anderson classification. Injury 42(12), 1408-1415 (2011).

23. Klein, S. L. \& Flanagan, K. L. Sex differences in immune responses. Nat. Rev. Immunol. 16(10), 626-638 (2016).

24. Reardon, S. Infections reveal inequality between the sexes. Nature 534(7608), 447 (2016).

25. Steinmetz, S., Wernly, D., Moerenhout, K., Trampuz, A. \& Borens, O. Infection after fracture fixation. EFORT Open Rev. 4(7), $468-475$ (2019).

26. Mensink, G. B. et al. Overweight and obesity in Germany: results of the German Health Interview and Examination Survey for Adults (DEGS1). Bundesgesundheitsblatt Gesundheitsforschung Gesundheitsschutz 56(5-6), 786-794 (2013).

27. Schneider, S., Mohnen, S. M. \& Pust, S. The average age of smoking onset in Germany-trends and correlates. Int. J. Public Health 53(3), 160-164 (2008).

28. Debus, F. et al. Numbers of severely injured patients in Germany a retrospective analysis from the DGU (German Society for Trauma Surgery) Trauma Registry. Dtsch. Arztebl. Int. 112(49), 823-829 (2015).

29. Tamayo, T., Brinks, R., Hoyer, A., Kuß, O. S. \& Rathmann, W. The Prevalence and incidence of diabetes in Germany. Dtsch. Arztebl. Int. 113(11), 177-182 (2016).

30. Kortram, K. et al. Risk factors for infectious complications after open fractures a systematic review and meta-analysis. Int. Orthop. 41(10), 1965-1982 (2017).

31. Metsemakers, W. J. et al. Fracture-related infection: a consensus on definition from an international expert group. Injury 49(3), 505-510 (2018).

\section{Acknowledgements}

We thank the Federal Statistical Office of Germany (Destatis) for their support of this work.

\section{Author contributions}

V.A. conceptualized the study, M.R. and N.W. analysed the data and wrote the main manuscript text, S.L. prepared Figs. 1, 2 and 3. All authors interpreted the data, reviewed, and approved the manuscript.

\section{Funding}

Open Access funding enabled and organized by Projekt DEAL.

\section{Competing interests}

The authors declare no competing interests.

\section{Additional information}

Correspondence and requests for materials should be addressed to M.R.

Reprints and permissions information is available at www.nature.com/reprints.

Publisher's note Springer Nature remains neutral with regard to jurisdictional claims in published maps and institutional affiliations. 
(c) (i) Open Access This article is licensed under a Creative Commons Attribution 4.0 International cc) License, which permits use, sharing, adaptation, distribution and reproduction in any medium or format, as long as you give appropriate credit to the original author(s) and the source, provide a link to the Creative Commons licence, and indicate if changes were made. The images or other third party material in this article are included in the article's Creative Commons licence, unless indicated otherwise in a credit line to the material. If material is not included in the article's Creative Commons licence and your intended use is not permitted by statutory regulation or exceeds the permitted use, you will need to obtain permission directly from the copyright holder. To view a copy of this licence, visit http://creativecommons.org/licenses/by/4.0/.

(C) The Author(s) 2021 